Social Sciences, Humanities and Education Journal (SHE Journal)

Volume 1 (3) 93 - 102, September 2020 | ISSN: 2720-9946 (Online) | ISSN: 2723-3626 (Print)

The article is published with Open Access at: http://e-journal.unipma.ac.id/index.php/SHE

\title{
BREAST IRONING: A RAPE OF THE GIRL-CHILD'S PERSONALITY INTEGRITY AND SEXUAL AUTONOMY
}

Titi Christiana Falana $\bowtie$, Department of Philosophy, Ekiti State University, Ado-Ekiti, Ekiti State, Nigeria.

\begin{abstract}
Breast ironing also known as breast flattening, has been considered as one of the most widespread and systematic violations of the universal human rights to personal integrity and sexual autonomy perpetuated against the girl child . This exhilarating practi ce which is typically carried out by the girl's mother on the pretext of protecting the female child from teenage sexual harassment and rape, early pregn ancy and dropping out of school is unfortunately done to protect family name. Employing the qualitative research approach and the expository analytic method, this research reveals that this practice has ensuring clinical, psychological and social consequences on the female victim. The paper considers this practice a rape based on the fact that the female victim's consent is never sought. Natural sense of justice demands that the victim whose personality integrity and right to sexual autonomy was to be defiled and destroyed deserves to give an informed consent. Therefore, the paper concludes that this harmful practice is an abuse because it violently violates the girl child right full sexual autonomy and right to possess natural physiological endowment that adorns a woman. This paper therefore recommends that strict laws and penalties should be promulgated to totally abolish and eradicate this barbaric and horrific mutilation.
\end{abstract}

Keywords: Breasts, Girl-Child, Ironing, Mutilation, Rape, Rights, Sexual, Violation.

$\bowtie$ Titichristiana@yahoo.com

Citation: Falana, T. C. (2020). Breast ironing : A rape of the girl -child's personality integrity and sexual autonomy. Social Sciences, Humanities and Education Journal (SHE Journal) , 1(3), 93 - 102. DOI: $10.25273 /$ she.v1i3.7596

\section{(cc) BY-NC-SA}

Published by Universitas PGRI Madiun. This work is licensed under the Creative Commons Attribution NonCommercialShareAlike 4.0 International License. 


\section{INTRODUCTION}

Breast ironing is one amongst the numerous despicable gender-based violence against the girl child. Genderbased violence is a problem that affects millions of girls and women, transversely boundaries of culture, religion, socio economic class, education, age and other levels of human social intercourse. It has been documented as a human rights issue that manifests itself in physical, psychological, social, and cultural forms (Edor 2005). This form of violence has been regarded by many as one of the most pervasive of human rights violations, denying women and girls' equality, security, dignity, self-worth, and their right to enjoy fundamental liberties (Robinson 2019). Such violence is highly prevalent within the family, remains widely socially tolerated and is often a cycle of abuse that manifests itself in an endless variety of forms. Various forms of such violence have been recognized globally, such as female genital mutilation and forced marriages (Simpson 2018). However there exists other form of violence which has been rendered invisible due to silence. A prominent example includes the practice of breast ironing.

The focus of this paper is to determine whether the practice of breast ironing could be rightly considered as a cultural practice that is imperative (essential); or whether it could be ideally seen as an unnecessary and callous cultural practice that constitutes a brute and violent violation of the girl child's right to sexual autonomy and right to physical integrity. With the aid of expository analysis the paper reveals that considering the clinical, psychological and physiological complications and problems associated to breast ironing and coupled with the fact that the purported reason for which breast ironing has been perpetuated from historic time remains unabated, therefore, the practice of breast ironing is not only an unnecessary abuse of the girl child but more significantly a violent violation of the girl child' right to sexual autonomy and right to physical integrity.

Consequently, this paper considers breast ironing as a public rape of the girl child's physical integrity, sexual integrity and right to sexual autonomy with the consent of the society. The mortal impact of this practice on the girl child arising from its clinical and psychological complications can never be obliterated in the life time of the girl. Most regrettably this senseless public rape is a carried out with the express and tacit consent of the mother. This has been one of the major factors that has consisted a push back to concerted effort made to abolish this obnoxious and enduring harmful practice. The paper concludes that this obnoxious practice could be metaphorically considered as punishing the she-goat for the iniquities of the he-goat. It therefore recommends that all well-meaning men and women of goodwill globally must rise up in condemnation and work assiduously to see to the end of this barbaric practice that mutilates the physical integrity of the girl-child.

\section{WHAT IS BREAST IRONING?}

Breast ironing is otherwise referred to as breast flattening. It is the consistent pounding and massaging of a pubescent girl's breasts, using hard or heated objects, in an attempt to retard their development or in the extreme to make them disappear. Breast ironing may be simply defined as the pounding and massaging of a pubescent girl's breasts, using hard or heated objects, to try to make them stop developing or disappear. Julie Ada Tchoukuo in her work titled Introducing the Practice of Breast Ironing as a Human Rights Issue in Cameroon, opines that, "breast ironing, usually referred to as another form of mutilation, is a practice whereby a young girl's developing breasts are pounded, pressed or massaged with an object usually heated in a wooden fire, to make them stop developing, grow more slowly or 
disappear completely" (Tchoukuo, 2014, pp. 10). Expressing similar concern, Bawe Rosaline Ngunshi, opined that "breast ironing also known as a form of mutilation is another weird practice whereby pubescent girl's breasts are flatten. This involves pounding and massaging the developing breasts of young girls from about eight years with hot objects to try to make them disappear" (1966: 5). This mutilation commences when the child is eight years of age because at this age she is nearing puberty and the very first changes that occurs in puberty that begin at about this age is gradual development of breast.

The objects used in carrying out this practice vary; however, the most widely used implement for breast ironing is a wooden pestle normally used for pounding fufu, eba, yam, etc. Other objects include grinding stones, black fruits, plantain peels, mortar pestles, coconut shells, ladles, spatulas or hammers, all carefully heated over burning coals. With these objects, mothers consistently press and iron their daughters developing breasts to destroy any indication of emerging womanhood. The massage could last from one week to several months depending on how resistant the breasts are and also depending on how resistant the victim or her body is to the practice. Sometimes, the heated objects are used twice a day for weeks or months to crush the budding breast. It should be asserted that "breast ironing is possible because the breast is nothing but the tissue overlying the chest muscles otherwise known as pectoral muscles. In other words, breasts consist of fatty tissues that is why they are susceptible to ironing-they can be dissolved or melted by consistent ironing" (Bartholomew, 2016, pp. 31).

Typically, women start developing breasts between the ages of 8-15 hence, breast ironing might probably begin at this young age. This has become problematic due to the age of puberty occurring at younger ages in females in the past decade, with studies showing that women of African descent have a higher rate of young breast development, with some experiencing breast growth by the age of 7 (Pharmacy Times, 2010; Ogar \& Edor 2020). It is also more likely for young girls to undergo the tradition if they begin developing breasts younger, with statistics stating that girls who experienced puberty before age 9 were $50 \%$ more likely to have their breasts ironed (Ngunshi, 1966). A critical look around one's vicinity would incredibly reveal that even some female children of six years of age have begun developing breasts. And unfortunately, the attraction this holds for their male counterparts cannot be wished away. Hence, the flattening of the breast is believed to help prevent young women from unwanted attention or rape, as well as to delay sexual activity which could lead to early pregnancy. Breasts are considered a sign of sexual readiness in many cultures so if the breasts are removed, it is believed that women will receive less sexual attention (Tchoukou, 2014). It may be plausibly argued that no superior logic can disprove this fact.

It has been argued that the practice of breast ironing has no connection with religion, ethnicity, wealth or formal education, urban or rural dwelling. This practice is not limited to rural areas or poor families where women are perceived to be uneducated, ignorant or unexposed to women's equality or children's rights, but is also reported to be prevalent in urban areas where women are more educated and exposed. To validate this empirical statement, Tapscott observed that "wives of parliamentarians and ministers also iron the breasts of their daughters without the knowledge of their husband" (2012, pp. 27).

\section{DIFFERENCE BETWEEN BREASTS IRONING AND BREASTS MASSAGING}

It is pertinent to distinguish between breast massaging and breast ironing. This becomes necessary at this point because some people are in the 
habit of using the term interchangeably to imply the same thing. However, research reveals that both are not the same because they are practiced for different reasons. For the records, breast massaging is an ancient practice basically on breastfeeding mothers to enhance the flow of milk for the baby's consumption. It is also considered helpful during the time of weaning the child. On the other hand, breast ironing is a practice of mutilating a teenage girl's developing breasts through pounding, pressing or massaging with an object usually heated in a wooden fire, to make them stop developing, grow more slowly or disappear completely.

It is germane to underscore that the basic difference between breast massaging and breast ironing is that while the former is a willful activity in the sense that the one whose breast is to be massage must be an adult who already is a mother; the latter is imposed on its victims who are usually girls between the ages of eight and fourteen who have started developing breasts. It is usually done by a female relative close to the victim.

\section{WOMEN RESPONSIBLE FOR BREASTS IRONING}

It germane to observe that across cultures and geographical climes women (the girl's mother, grandmother, aunt or guardian,) typically carried out this practice and the simple reason for this is the fact that it has to do with the private part of a female. Of course the father couldn't have been the one to invade his daughter's privacy, hence the woman is commanded by culture (even against her wish) to carry out this cultural ordinance. Commonsense morality would never allow a male or the father to behold the private region of her pubescent daughter and this is why the mother has to either freely or under compulsion carry out this rape with the consent of the society. Societies where this cultural practice prevails have adduced several reasons why this practice became culturally imperative. These reasons include, to protect the girl from teenage sexual harassment and rape, early pregnancy, and to ensure the girl pursues education rather than be forced into early marriage. These reasons where precipitated for instance, by the background fact that breast ironing is mostly practiced in parts of Cameroon, where boys and men may think that girls whose breasts have begun to grow are ready for sex. This is a very formidable argument based on empirical fact. The first point of attract in a female body is the breasts and female pubescent girls unknowingly start sending sexual signals to their male counterparts with their budding succulent breasts. Ultimately the ground reason for ironing the girl child's breasts is to forestall the future tarnishing of the family name. The family rapes their female children of their physical integrity and sexual autonomy with the consent of culture to protect their family name.

\section{CULTURE AND THE ORIGIN OF BREAST IRONING}

The question that arises in respect to the origin of this practice is whether it has been historically part of a particular culture or whether it is merely a practice that has acquired the status of culture over time. A further question that arises is whether it is a practice that was abandoned and is re-emerging or a practice that has been on-going but is now more visible. These questions became imperative because it has often been argued that the principal justification of breast ironing is that it is a cultural imperative; an imperative because it is meant to preserve core moral values of society. These values include chastity and abstinence from premarital sex. In theory, a distinction has been made between culture as a system and practices deemed to be culture. Sewell asserts that "most theoretical writings on culture have presumed that the concept of culture as a system is in conflict with the concept of culture as practice" (2013, pp. 28). Scholars who are apologists of culture as 
a practice insist that culture is a 'sphere of practical activity carried out via willful action, power relations, struggle, contradiction and change (2013, pp. 30). While proponents who project culture as a system argue that culture is a system of norms, values and social relations.

The term culture has been defined in various ways. It has been described as a prime source of one's identity and has also been regarded as the source of 'selfdefinition, expression and sense of group belonging (Edor 2016). Hence, culture can be said to indicate a way of acting, thinking and doing things that is distinctive to a certain group of persons. Anthropologists generally use the term culture to refer to a society or a group in which many people live and think in the same way (Northoff 2013). According to this definition, culture includes inherited ideas, beliefs, values and knowledge which constitute the shared basis of social action. In this light, an inherited idea or belief through usage and transfer to succeeding generations can be regarded as culture.

From the above, it can be argued that for certain beliefs or behaviors to be viewed as culture; it is not a requirement that it be deeply embedded and historically part of a specific culture. Therefore the mere fact that a specific belief is practiced and passed on from generations to generations can lead to it being regarded as part of culture. It should be added also that society A can borrow something from society B and it automatically become part of the culture of society $\mathrm{A}$.

Cultural materials and traditions can be transmitted orally from one generation to another. In this regard, Wilson asserts that oral tradition is the process in which history, stories, religious beliefs are passed on from generation to generation (Wilson, 38). She further affirms that for the African people, oral tradition is linked to their way of life, in that it is regarded as the primary means of conveying culture and attitudes. Therefore in this way, it is possible for a society to transmit oral history, oral law, oral traditions and other knowledge across generations without a writing system. Heinge holds that, "for a material to be regarded as cultural material or tradition that has been transmitted orally, it is important that such material be held in common by a group of people over several generations" (Heinge, 2013, pp. 39). It may therefore be argued that the practice of breast ironing is one which can be regarded as cultural material transmitted orally. This is premised on the fact that this practice has been held in common by a group of people over several generations, in that, it is common among all 250 ethnic groups in Cameroon and has been passed on through generations.

In places where breast ironing is practiced in Cameroon, it is a common practice for every household. This implies that it is a practice held common by everyone under the jurisdiction of that particular culture. Now the question is, at what point did this practice began in Cameroon which studies have revealed to be its epicenter. Taku in her work titled United Nations Children's Fund 'Domestic Violence against Women and Girls' revealed that:

It is difficult to state exactly when this practice began or at what point the motivation behind the practice of breast massage changed. And the only evidence as to the history of this practice is the fact that today's elderly women also suffered this treatment (Taku, 2014, pp. 45).

However, it is worth noting that, from other research, older women did not suffer breast ironing but the ancient practice of breast massage. She further argues that this practice is deeply rooted in custom mainly because mothers who tolerated it were told by their own mothers that it was done to protect them. As a result mothers who endured this practice also repeated the gesture to protect their own daughters and this 
continued in vicious circle. She also argues that breast ironing is merely 'a vicious circle that survives through ignorance more than tradition' (Taku, 2012. pp. 47). From this, it can be deduced that there is oral tradition that speaks at length about this practice. Rebecca Tapscott's in a works, Understanding Breast Ironin: A Study of the Methods, Motivations, and Outcomes of Breast Flattening Practices in Cameroon, maintained that:

Findings on the history of this practice indicate that breast ironing is not an ancient 'traditional practice. Thus, this practice became prevalent in Cameroon with urbanization, in that, women who migrated to cities became concerned about the safety of their daughters. Therefore, the old practice which was used to soothe and massage the breasts was revived and adapted (Tapscott, 2012. pp. 48).

Thus far may be adduced that breast ironing originated in Cameroon at certain time and has since them became an essential cultural practice. Meanwhile, the concept breast ironing has it origin from the Cameroonian tradition and culture which is breast shaping or massaging. This culture is premised to the development and nourishment of the mother's milk for the breast feeding of her baby. It follows that the practice is solely for adults who are willing and of course are mothers. Unlike breast ironing whose practice is centered on children. More so, from the onset, breast shaping or massaging has been in existence which is successfully replaced by the breast flattening or ironing.

Notwithstanding the difficulty in establishing the actual time when breast ironing originated, there are however some historical antecedence and factors that instigated societies in Cameroon where breast ironing is predominately practice to originate this physical mutilation. These factors include decline of teenage/early marriage practice, incessant sexual abuse of children and tarnishing of family name (honour), and religious fanaticism.

i. Decline of teenage/early marriage practice: From historic time, Cameroon is renowned for the culture of teenage and early marriage practice. Teenage girls were married off as soon as they experience their first menstrual period. Moreover, pubescent girls were betrothed when in infancy and are handed over to their betroths in marriage as soon as their physiological organs are developed and become suggestive to men. As long as this was the practice, before teenage girls ever got to be abused they were already married off. However, with time the practice of teenage and early marriage steadily declined as a result of civilization, urbanization and sustained education on the negative consequences of teenage marriage.

Consequently, with the drastic decline of this practice, the pubescent girl child and young girls became vulnerable to philanderers and allegedly there were widespread cases of sexual abuses resulting in early pregnancies. Increasingly, young girls who are victims started dropping out of school. Against this backdrop, to protect the girl child from this unfortunate situation the culture of breast ironing was introduced.

ii. Sexual abuse of children (premarital sex) and the fear of tarnishing family name: The steady decline of teenage and early marriage practice which snowballed into sexual abuse of children and widespread of premarital sex constituted a great dishonour to families of victims. 
Hence, to forestall the disgrace that might result from the child possibly raped by migrates or locals because of their impressionable state and curiosity, the breasts of pubescent girls were ironed. With this, it is believed that families' prestige and honour were preserved.

iii. Religious fanaticism: One of the factors that influenced parents to subjecting their teenage girls to the harrowing experience of breast ironing is religious fanaticism. Since most pubescent girls may not be able to practice abstinence the only viable option to save sex would have been the use of contraceptives. However, most families were conservatives whose religious fanaticism cannot allow them permit their children the use of contraceptives. Coupled with the fact that religious precepts outlaw premarital sex, the only hard option was to iron the breasts of these impressionable daughters to retard and slow the growth of their breast thereby delaying it sending signals of readiness to their male counterparts for ready for sexual intercourse.

These three reasons combined has been the reason and driving force of breast ironing for ages. On the strength of these three cardinal reasons advocates of breasts ironing believe that breast ironing is a cultural imperative that must be allowed to continue unabated for the moral sanctity of the social order. On the basis of this, even if the girl child suffers any harm, it is worth the price for the good for society. In other words, it is a necessary evil. Now the question is, can breast ironing be rightly considered a cultural imperative or on the contrary a gross violation of the girl child rights of personal integrity, personal liberty and sexual autonomy, or even something worse? A case can be plausibly made that breast ironing is a rape of the personality integrity and sexual autonomy of the victim.

\section{BREAST IRONING AS A RAPE OF THE PERSONALITY INTEGRITY AND ABUSE OF SEXUAL AUTONOMY}

Breast ironing cannot be considered as a reasonable cultural practice that merits to be called a cultural imperative. The reason for this position is that even in the societies where it was practiced sexual harassments and teenage pregnancies were still evident. Flatting of the breast or retarding its development cannot remove sexual urges from the girl child. Again, apart from the breasts, there other physiological organs which are sexually suggestive. At this point one may also ask, what happens to the male child who approached the girl child for possible sexual activity. Why punish the she-goat the crimes of the he-goat?

The practice of breast ironing is conceived to be a child abuse deteriorating the female child's quality which affect her physiologically and psychologically as it distort her social life. From the inception of this practice it has been misconstrued from its original sense into gender based violence on the girl child forced against her wish to satisfy the cravings of her parents. Breast ironing is considered an abuse because of the clinical and psychological consequences that necessarily accompanies it.

Breast ironing has caused more harm than good to women. Contrary to the supposed reasons adduced as its justification as a cultural imperative, breast ironing has not in any way helped prevent unwanted attention, rape, or teenage pregnancy in the societies where it has been practiced. Rather it has infamously positioned women who were its victims for a lifetime of difficulties including pain, inability for breastfeeding, psychological trauma, and in some situations breast cancer. A practical example that demonstrates the fact that breast ironing is indeed an abuse and distortion of the girl child's physical 
integrity is the account of a young woman named Gaelle, who is now twenty six (26), who spoke about her experience of breast ironing as a girl stating, and I quote:

At night, my mother would make me wear a really tight elastic band around my chest. During the day, she'd massage me with a spatula, a pestle, a stick or a rock. It really hurt. I asked her to stop and eventually she did. But after the ironing, my breasts grew really fast. Like really, really fast. I was so ashamed. I wanted to hide them. People on the street would scream at me about my boobs. By my twenties, my breasts started to sag like those of a 50-year-old woman. I'm reluctant to undress in front of people. Sometimes, I keep my top on when I have sex with my boyfriend. I really resent my mother (Bidan, 2015).

This woman, like many others, has felt the harsh realities of breast ironing. It destroys more than a girl's breasts but also her confidence. There is also the story of Emmanuelle, a 23-year-old, who spoke about her mother ironing her breasts and the pain that came with the massaging, describing it "as if she was stabbing something into my chest" (Bidan, 2015). She goes on to say that her cousin raped and impregnated her when she was only 13 years old and because of the ironing she no longer had breasts to produce milk to feed her child (Bidan, 2015). Both these women describe examples of harms which have had long term negative effects on them that are a result of breast ironing but also highlight that this method is not an effective method against rape or pregnancy. Some of the concrete clinical and medical complications associated to breast ironing are discussed below:

1. Breast Cancer: Breast cancer is a disease in which cells in the breast grow out of control. According to medical experts, a breast is made up of three main parts: lobules, ducts and connective tissue (Breast Cancer Linkage Consortium 1999). The lobules are the grand that produce milk, the ducts are tubes that carry milk to the nipples and finally, the connective tissues (which consists of fibrous and fatty tissues) surrounds and holds everything together. It is these tissues that breast ironing destroys thereby temporarily retarding the growth of the breast and later triggering the abnormal growth of these tissues thereby causing cancer.

2. Cysts: A cyst is a sac-like pocket of membranous tissue that contains fluid, air or other substances (Falk \& Bunkin 1953). It can grow anywhere in the human body or under the skin. There are about about 13 different kinds cyst: breast cyst, epidermis, sebaceous, ganglion, ovarian, chalazae, etc. Breast ironing has been found to have caused breast cysts to most of its victims.

3. Abscesses: Abscesses can be defined as a confined pocket of pus that collects in tissues, organs or spaces inside the body (Hackett 2001). When an area in the body becomes infected the body's immune system sends white blood cells to fight the infection. These cells collect and combine with the damaged tissue and germs, creating liquid called pus. This has been one of the likely consequences of breast ironing

4. Dissymmetry of the breast: Breast ironing also causes dissymmetry of the breasts. This is a physiological condition whereby the two breasts are not of the same shape and size. In some extreme cases it even causes the complete disappearance of one or both breasts. Imagine a young lady with two unequal breasts or even without breast at all! This distorts the physical integrity of the victim because breasts have a very important aesthetic value. The sight of this has both psychological and social consequences on the victim and it invariably affects the individual selfconcept, confidence, identity and esteem.

5. Breast Itching and Discharge of Milk: It has also been reported that some 
victims of breast ironing usually suffer from conditions like breast itching and discharge of milk 9 Kantorowska 2016). You can imagine what degree of discomfort and embarrassment this might be causing those suffering from it.

\section{CONCLUSION}

From the foregoing expository analysis of the culture of breast ironing, it is unarguably clear breast ironing has caused more harm than good to women (if at all it has any positive value). It has inflicted untold life time clinical and psychological burden on its victims; these include pain, inability for breastfeeding, psychological trauma, cancer etc. On the strength of the findings of this research therefore, it is germane to argue that the harrowing practice of breast ironing is a rape of the victim's personality integrity, personal liberty, and the right to sexual autonomy. It is an abuse of the girl child and a patriarchal injustice that punished the she-goat for the atrocities of the hegoat. The paper recommends that society must begin to device a new method of socializing the male child to understand the he too is expected to develop the virtues of continence, purity and selfdiscipline towards women. He must equally be made to understand that his manhood is his dignity and as such virginity must be a priceless virtue he must maintain. On the legal perspective, strict laws and penalties must be enacted to totally delete this inhumane and senseless practice.

\section{REFERENCES}

Bartholomew, L. (2016). Patriarchy and harmful practices: not a problem for us? Seen and Heard, 26(3), 29-37.

Bidan, M. (2015). The victims of Cameroon's breast ironing tradition, London: Routledge.

Breast Cancer Linkage Consortium, T. (1999). Cancer Risks in BRCA2 Mutation Carriers. JNCI Journal of the National Cancer Institute,
91(15),

1310-1316.

https://doi.org/10.1093/jnci/91.15 .1310

Edor, J. E. (2005). The inductive predicament as an indispensable sable evil for practical life. Sophia: An African Journal of Philosophy, 8(1), 110-115.

Falk, H. C., \& Bunkin, I. A. (1953). Intraperitoneal cysts simulating ovarian cysts. Obstetrical and Gynecological Survey, 8(5), 738739.

https://doi.org/10.1097/00006254 $\underline{-195310000-00010}$

Hackett, T. (2001). Abscesses and Cellulitis. In Veterinary Emergency Medicine Secrets (pp. 135-137). https://doi.org/10.1016/b978-156053-421-1.50036-3

Henige, D. O. (2013). The Nomenclatures of Orality and Their Implications, Massachusetts: Hendrickson Publisher Inc..

Kantorowska, A., Wei, J. C., Cohen, R. S., Lawrence, R. A., Gould, J. B., \& Lee, H. C. (2016). Impact of donor milk availability on breast milk use and necrotizing enterocolitis rates. Pediatrics, 137(3). https://doi.org/10.1542/peds.2015 $-3123$

Ngunshi, R. (1966). Breast Ironing: A Harmful Traditional Practice in Cameroon, Gender Empowerment and Development, Tennessee: The South Western Company.

Northoff, G. (2013). What is culture? Culture is context-dependence! Culture and Brain, 1(2-4), 77-99. https://doi.org/10.1007/s40167013-0008-y

Ogar, T. E., \& Edor, J. E. (2020). Creative Cultural Synergy: Towards the Africa of the Future. PINISI Discretion Review, 4(1), 135-150.

Rebecca, J. C. (1994). "State Responsibility for Violations of Women's Human Rights", Harvard Human Rights Journal. 
Robinson, F. (2019). Breast ironing. In BMJ (Online) (Vol. 365). https://doi.org/10.1136/bmj.11790

Sewell, W. (2013). The Concept of Culture, England: Lion Hudson.

Simpson, H. (2018). Global midwifery series: Raising awareness of breast ironing practices and prevention. Practising Midwife, 21(5), 38-41.

Tapscott, R. (2012). Understanding Breast Ironing: A Study of the Methods, Motivations and Outcomes of Breast Flattening Practices in Cameroon, Feinstein International Center.

Tchoukou, A. (2014). Introducing the practice of breast ironing as a human rights issue in Cameroon, J Civil Legal Science. 